\title{
Ekspresi TGFB1 Setelah Pemberian Ekstrak Gel Aloe Vera Pada Soket Pencabutan Gigi Tikus Wistar
}

\author{
Niswatun Chasanah $^{1}$, Achmad Bashori ${ }^{2}$,Agung Krismariono ${ }^{3}$ \\ ${ }^{1}$ Mahasiswa Ilmu Kedokteran Dasar Jenjang Magister Fakultas \\ Kedokteran Universitas Airlangga Surabaya \\ ${ }^{2}$ Departemen Farmakologi Fakultas Kedokteran Universitas Airlangga \\ Surabaya \\ ${ }^{3}$ Departemen Periodonsia Fakultas Kedokteran Gigi Universitas \\ Airlangga Surabaya \\ email : niswa.drg@gmail.com
}

\begin{abstract}
ABSTRAK
Pencabutan gigi merupakan tindakan bedah minor dan proses penyembuhan membutuhkan waktu yang lama untuk dapat dilakukan perawatan rehabilitatif, yaitu perawatan gigi tiruan. Aloe vera dikenal sebagai healing plant untuk mengobati luka dan luka bakar. Komponen Aloe vera berperan untuk merangsang produksi sitokin. TGF 1 merupakan sitokin yang multifungsi oleh karena aktivitasnya yang luas termasuk terhadap regulasi dari sintesa dan degradasi komponen ECM yang merupakan hal penting untuk proses penyembuhan luka. Membuktikan peningkatan ekspresi TGF 1 setelah pemberian ekstrak gel Aloe vera dengan konsentrasi 45\%,60\%,90\% pada soket pencabutan gigi tikus wistar. Populasi sampel adalah 28 tikus wistar dengan syarat inklusi dan terbagi menjadi 4 kelompok. Metode pengekstrakan dengan cara freeze drying (liofilisasi). Satu kelompok kontrol (P1) dan 3 kelompok perlakuan dengan pemberian ekstrak gel Aloevera konsentrasi 45\% (P2), konsentrasi $60 \%$ (P3), konsentrasi 90\% (P4). Pencabutan gigi incisivus lateral kanan kemudian diaplikasikan ekstrak gel Aloevera kedalam soket pencabutan dan dilakukan suturing. Terminasi dilakukan pada hari ke 7 pasca pencabutan gigi. Pembuatan preparat melalui pengecatan Imunohistokimia (IHC). Uji hipotesis dengan Kruskal Wallis. Terdapat peningkatan yang bermakna pada setiap kelompok perlakuan $(p \leq 0,05)$. Terdapat peningkatan ekspresi TGFB1 setelah pemberian ekstrak gel Aloe vera konsentrasi 45\%,60\%,90\% pada soket pencabutan gigi tikus wistar.
\end{abstract}

Key word : Ekspresi TGFß1, Ekstrak Aloevera gel, Freeze drying, Penyembuhan soket alveolar 


\begin{abstract}
Tooth extraction is a minor surgical procedure and the healing process takes a long time to be able to do rehabilitative treatments, namely denture treatment. Aloe vera is known as a healing plant to treat wounds and burns. Aloe vera components play a role in stimulating cytokine production. TGF $\beta 1$ is a multifunctional cytokine due to its extensive activities including regulation of synthesis and degradation of ECM components which are important for wound healing. To prove the increase in TGF 1 expression after administration of Aloe vera gel extract with a concentration of 45\%, 60\%, 90\% in the wistar rat tooth extraction socket. The sample population was 28 wistar rats with inclusion conditions and divided into 4 groups. Extraction method by freeze drying (lyophilization). One control group (P1) and three treatment groups with 45\% (P2) Aloevera gel extract concentration, $60 \%$ concentration (P3), 90\% concentration (P4). Extraction of the right lateral incisor was then applied to Aloevera gel extract into the extraction socket and carried out by suturing. Termination is done on the 7th day after tooth extraction. Preparation of preparations through Immunohistochemical staining (IHC). Hypothesis testing with Kruskal Wallis test. there was a significant increase in each treatment group $(p \leq 0.05)$ except in group P2 against P4 had no significant difference. There was an increase in the expression of TGF $\beta 1$ after the administration of Aloe vera gel extract concentration of $45 \%, 60 \%, 90 \%$ in wistar rat tooth extraction socket.
\end{abstract}

Key words : TGFB1 expression, Aloevera gel extract, freeze drying, Alveolar sockethealing 


\section{PENDAHULUAN}

Masalah utama kesehatan gigi dan mulut menurut survei riset kesehatan dasar (RISKESDAS) tahun 2013 menyebutkan bahwa indeks Decay Missing Filled Teeth (DMF-T) di Indonesia cukup tinggi, dimana indeks M-T (Missing Teeth) adalah

2,9 (rata-rata 290 gigi telah dicabut per 100 orang) dan rasio tambal dan cabut masih tinggi rata-rata adalah 1:4 yaitu satu tambal dan empat gigi yang dicabut serta hasil monitoring dan evaluasi tahun 2011 dibeberapa daerah rasionya bisa mencapai

1:10 (Kementrian Kesehatan RI,2012 cit Sari,2018). Data tersebut menunjukkan bahwa angka pencabutan gigi di Indonesia masih tinggi.

Pencabutan gigi merupakan salah satu tindakan bedah minor yang dilakukan dokter gigi untuk menghilangkan gigi dari soket gigi dan menimbulkan luka (Permatasari,2012). Luka pencabutan gigi dapat menyebabkan terjadinya komplikasi dengan jangka waktu penyembuhan yang berbeda. Perdarahan pasca pencabutan, pembengkakan, dry socket, serta infeksi, merupakan beberapa komplikasi yang terjadi pasca pencabutan gigi (Wray et al,2003). Pada pasien yang telah dilakukan pencabutan gigi, akan dilakukan perawatan rehabilitasi dengan gigi tiruan, baik lepasan maupun cekat. Pada pembuatan gigi tiruan lepasan maupun cekat seperti implant denture, diperlukan waktu beberapa bulan untuk dapat direhabilitasi dengan baik. Hal ini merupakan waktu yang panjang bagi seorang pasien untuk mendapatkan fungsi estetik dan fungsi kunyah kembali dan selama beberapa waktu akan terjadi resorpsi signifikan dari ridge tulang alveolar yang sangat berpengaruh terhadap kualitas rehabilitasi yang dilakukan (Schropp et al,2003;Jung et al,2013 cit Khoswanto 2016).

Aloe vera dikenal sebagai healing plant. Tanaman ini secara tradisional digunakan untuk mengobati luka dan luka bakar (Choi et al,2001). Aloe vera mengandung acemannan, phytosterol, beserta komponen aktifnya yang mengakibatkan penyembuhan luka lebih cepat melalui stimulasi produksi faktor pertumbuhan, angiogenesis, proliferasi dari deposisi fibroblas dan kolagen (M.D. Boudreau,2006). TGF 1 merupakan sitokin yang multifungsi oleh karena aktivitasnya yang luas termasuk terhadap regulasi dari sintesa dan degradasi komponen ECM yang merupakan hal penting untuk proses penyembuhan luka.

Berdasarkan uraian diatas, Aloevera bermanfaat dalam proses pasca pencabutan 
Jurnal Biosains Pascasarjana Vol. 20 (2018) pp

(C) (2018) Sekolah Pascasarjana Universitas Airlangga, Indonesia

gigi yang ditandai oleh adanya biomarker

$T G F \beta$. Namun, pengaruh Aloe vera terhadap

biomarker tersebut masih belum jelas sehingga penelitian ini dirancang untuk membuktikan peran ekstrak gel Aloevera pada soket pencabutan gigi tikus wistar terhadap ekspresi $T G F \beta 1$.

\section{MATERI DAN METODE A.}

\section{Ekstrak gel Aloevera}

Daun Aloe vera dicuci bersih dengan aquadest kemudian dikupas kulitnya untuk mendapatkan gel (daging). Kemudian gel Aloe vera dicuci bersih dengan aquadest sampai lendirnya hilang, selanjutnya ditimbang dan didapatkan gel. Metode pengekstrakan dengan freeze drying. Freeze drying adalah metode pengekstrakan yang mempunyai keunggulan dalam mempertahankan mutu hasil pengeringan. Prinsip dasar freeze drying adalah menghilangkan kandungan air dalam suatu bahan atau produk. Liofilisasi adalah solusi farmasi untuk menghasilkan sebuah produk bubuk yang stabil (Arifin,2015). Aloevera mengandung air sebanyak $95 \%$. Sisanya berupa bahan aktif (active ingredients) antara lain minyak esensial, asam amino, mineral, vitamin, enzim, dan glikoprotein (Jatnika and Saptoningsih,2009). Aloevera ditimbang $1000 \mathrm{~g}$ dan diambil bagian gel kemudian didapatkan fase cair sebanyak 400ml (setelah diblender). Dari fase cair didapatkan 2,5gram Aloevera sediaan bubuk (hasil freeze drying). Jika 100\% $100 \mathrm{ml}$ maka terdapat 0,625 gram sediaan powder kering. Dari hasil tersebut, dibuat sediaan ekstrak gel Aloevera konsentrasi $90 \%, 60 \%, 45 \%$ dengan masing-masing konsentrasi tersebut ditambahkan CMC Na $3 \%$ sebagai basis gel.

\section{B. Unit Penelitian}

Penelitian ini adalah penelitian experimental laboratoris dengan rancangan randomized post test control group desain Sampel penelitian adalah tikus wistar (Rattus norvegicus) jenis kelamin jantan. Besar sampel adalah 28 yang terbagi menjadi 4 kelompok. Sebelum penelitian, kelompok sampel melalui proses aklimatisasi untuk penyesuaian dengan lingkungan. Kelompok sampel terdiri atas : Kelompok P1 : kelompok kontrol dengan pencabutan gigi (incisive lateral) dan diaplikasikan bahan basis gel (CMC 3\%) untuk memastikan bahwa basis gel yang digunakan untuk membuat ekstrak gel Aloevera tidak mempunyai pengaruh. Kelompok P2 : kelompok perlakuan dengan pencabutan gigi (incisive lateral) dan diaplikasikan ekstrak gel Aloevera konsentrasi konsentrasi $45 \%$ hingga soket penuh $(0,01 \mathrm{ml})$

Kelompok P3 : kelompok perlakuan dengan pencabutan gigi (incisive lateral) dan diaplikasikan ekstrak gel Aloevera konsentrasi konsentrasi $60 \%$ hingga soket penuh $(0,01 \mathrm{ml})$ 
Jurnal Biosains Pascasarjana Vol. 20 (2018) pp

(C) (2018) Sekolah Pascasarjana Universitas Airlangga, Indonesia

Kelompok P4 : kelompok perlakuan dengan pencabutan gigi (incisive lateral) dan diaplikasikan ekstrak gel Aloevera konsentrasi konsentrasi $60 \%$ hingga soket penuh $(0,01 \mathrm{ml})$. Setelah tindakan perlakuan, dilakukan suturing, dan terminasi pada hari ke-7. Fiksasi sampel (mandibula) dengan menggunakan formalin buffer $10 \%$ dan proses dekalsifikasi menggunakan EDTA $10 \%$ selama \pm

3bulan. Semua prosedur pada penelitian ini telah mendapat ethical clearance oleh Komisi Etik Fakultas Kedokteran Gigi Universitas Airlangga, Surabaya.

\section{Pemeriksaan IHC}

Proses pembuatan sediaan histologi yaitu fiksasi, dehidrasi, clearing, embedding, blocking, sectioning, staining, mounting, dan labelling (Jusuf,2009). Untuk mengetahui jumlah sel yang mengekspresikan TGF $\beta 1$ dilakukan pemeriksaan Histologi dengan prosedur pengecatan imunohistokimia. Sediaan imunohistokimia yang telah dilabel diamati dibawah mikroskop cahaya dengan pembesaran hingga 400x untuk melihat distribusi ekspresi dari TGF $\beta 1$, dalam 10 lapang pandang agar memudahkan membaca dan mencegah duplikasi sel. Data diperoleh dari hitungan rata-rata dalam 10 lapang pandang. Hasil perhitungan ditulis pada lembar kerja dan diambil nilai rata-rata per lapang pandang. Analisis data dengan uji statistik
Shapiro Wilk untuk mengetahui normalitas data selanjutnya dilakukan uji Kruskal Wallis untuk mengetahui komparasi yang bermakna terhadap peningkatan data yang terjadi.

\section{HASIL DAN DISKUSI}

Pada gambar 1 adalah gambaran mikroskopik jumlah sel yang mengekspresikan TGF $\beta 1$ diseluruh penampang soket pada kelompok kontrol soket gigi.

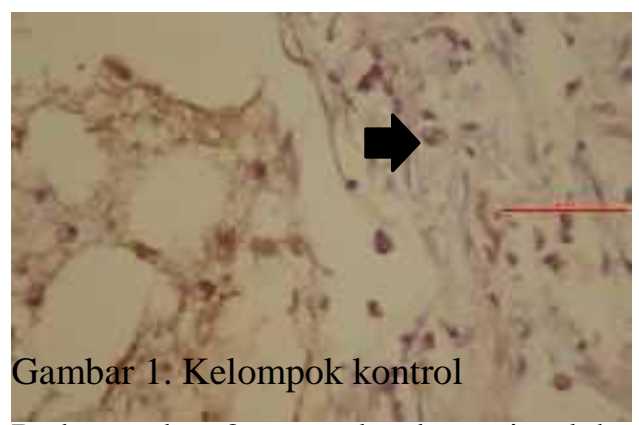

Pada gambar 2 nampak adanya jumlah sel yang mengekspresikan TGF 1 meningkat dibandingkan dengan kelompok kontrol.

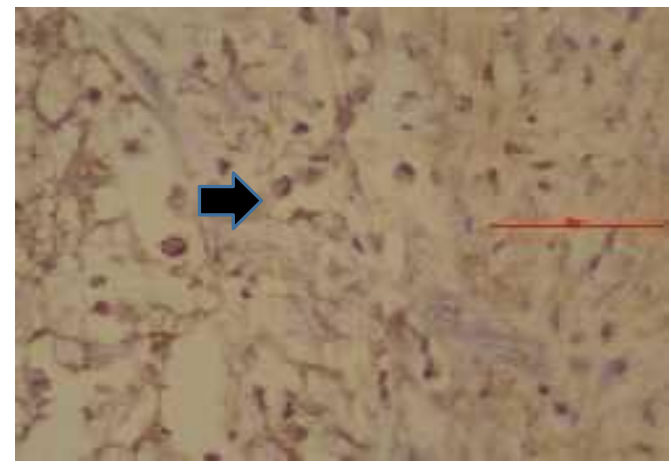

Gambar 2.Kelompok P2 (45\%)

Pada gambar 3 nampak adanya peningkatan yang cukup tajam terhadap jumlah sel yang mengekspresikan $T G F \beta 1$ pada penampang soket gigi. 


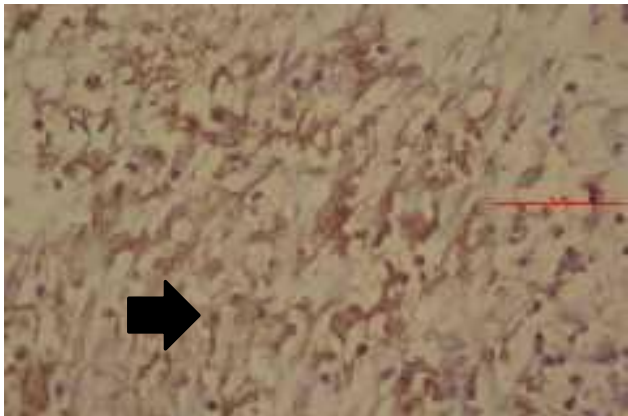

Gambar 3. Kelompok P3 (60\%)

Pada gambar 4 terjadi penurunan terhadap jumlah sel yang mengekspresikan $T G F \beta 1$ dibandingkan pada kelompok P3(60\%).

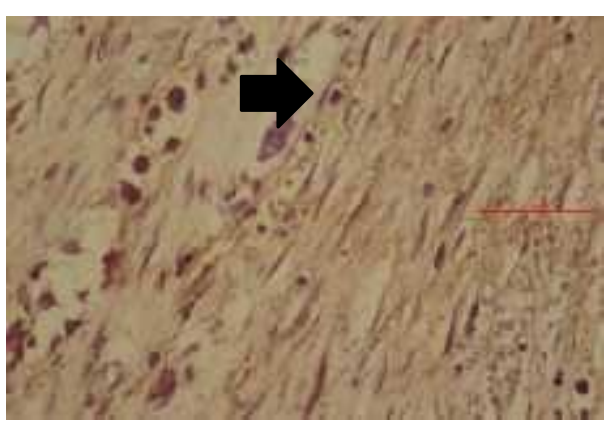

Gambar 4. Kelompok P4 (90\%)

Gambar 5 menunjukkan rerata dari jumlah sel yang mengekspresikan TGF $\beta 1$. Peningkatan tertinggi terjadi pada kelompok P3 yaitu kelompok perlakuan dengan pemberian ekstrak gel Aloevera konsentrasi 60\%. Selanjutnya diikuti oleh kelompok P4, P2, dan P1 (kontrol).

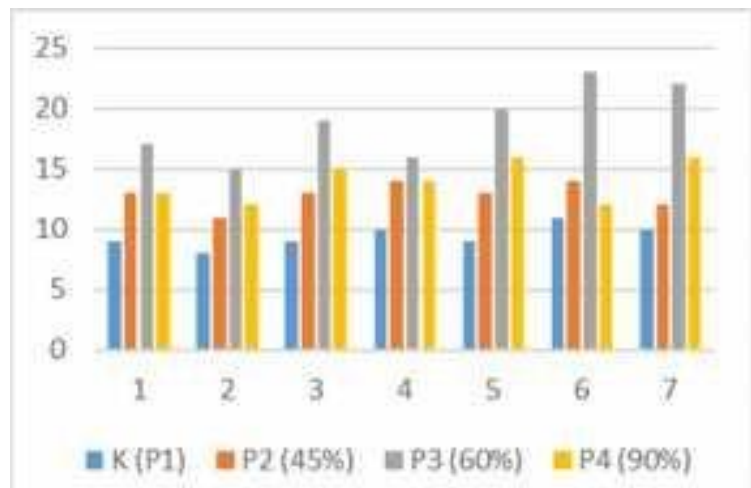

Gambar 5. Diagram batang terhadap rerata jumlah sel yang mengekspresi TGF $\beta 1$ pada kelompok perlakuan

Tabel 1. Data deskripsi terhadap jumlah sel yang mengekspresi TGF $\beta 1$ pada kelompok perlakuan

\begin{tabular}{|c|c|c|c|c|}
\hline \multirow{1}{*}{} & \multicolumn{4}{|c|}{ Jumlah TGFß1 Hari ke 7 } \\
\cline { 2 - 5 } & $\mathrm{K}$ & $\mathrm{P} 2$ & $\mathrm{P} 3$ & $\mathrm{P} 4$ \\
& $(\mathrm{P} 1)$ & $(45 \%)$ & $(60 \%)$ & $(90 \%)$ \\
\hline & 9 & $13 \pm$ & $19 \pm$ & $14 \pm$ \\
$\mathrm{X} \pm$ SD & $\pm 0,98$ & 1,07 & 3,02 & 1,73 \\
& & & & \\
\hline
\end{tabular}

Data penelitian yang ada dilakukan uji Shapiro Wilk untuk mengetahui normalitas data. Berdasarkan hasil perhitungan menunjukkan bahwa masing- masing data mempunyai distribusi normal dengan nilai $p$ berturutturut adalah

$0,609^{*}, \quad 0,294^{*}, \quad 0,747^{*}, \quad 0,240^{*} \quad(\mathrm{p} \geq 0,05)$.

Selanjutnya dilakukan uji hipotesis dengan Kruskal Wallis yang disebutkan pada tabel 2.

\begin{tabular}{|l|c|c|}
\hline Variabel & $\mathrm{n}$ & $\mathrm{P}(\mathrm{p}$ value $\leq 0,05)$ \\
\hline Jumlah & 28 & $0,000^{*}$ \\
TGF $\beta 1$ & & \\
\hline
\end{tabular}

Tabel 2. Uji komparasi

*signifikan

Data diatas menunjukkan hipotesis menolak H0 dan menerima H1 bahwa Ekstrak gel Aloevera meningkatkan jumlah sel yang mengekspresikan TGF $\beta 1$ dibandingkan dengan kelompok kontrol. Hal ini membuktikan bahwa ekstrak gel 
Jurnal Biosains Pascasarjana Vol. 20 (2018) pp

(C) (2018) Sekolah Pascasarjana Universitas Airlangga, Indonesia

Aloevera konsentrasi $45 \% .60 \% .90 \%$ dapat meningkatkan jumlah sel yang mengekspresikan TGFB1.

TGF $\beta 1$ adalah polipeptida yang terdapat dalam jumlah besar dan berpengaruh pada diferensiasi serta perkembangan jaringan, mengontrol respons imunologi, dan proses penyembuhan luka. Peningkatan TGF 1 mempengaruhi proliferasi dan diferensiasi sel mesenkim, dan peningkatan produksi ekstraseluler matriks pada proses penyembuhan luka (Poniatawski et al,2015). TGF $\beta 1$ secara langsung merangsang fibroblas untuk mensintesa kolagen dan fibronektin, serta menghasilkan matriks guna perbaikan jaringan.

Aloe vera merupakan salah satu tanaman yang berperan dalam proses penyembuhan dengan fungsi utama sebagai antiinflamasi dan immunomodulator (Jia,2008). Komponen aktif Aloe vera (lidah buaya) secara farmakologis terletak pada jaringan parenkim, yang disebut gel (Sharma et al, 2014). Komponen Aloe vera berperan untuk merangsang makrofag dan produksi sitokin. TGF $\beta 1$ merupakan salah satu sitokin yang yang terlibat dalam proses penyembuhan luka (Vijayalakshmia D dalam A.Penn et al,,2012). Mannose-6- fosfat yang terdapat dalam Aloe vera mempunyai peranan utama terhadap proses penyembuhan dan mempunyai pengaruh terhadap komposisi kolagen dan meningkatkan cross linking untuk kontraksi luka dan meningkatkan tensile strength (T. Reynolds and A. C. Dweck, 1999).

Proses penyembuhan luka pasca pencabutan gigi bersifat progresif hingga berlanjut pada proses osifikasi sehingga soket alveolar yang terbentuk tidak mengalami fibrosis. Peneliti berasumsi bahwa jumlah sel yang mengekspresi TGF $\beta 1$ pada kelompok P4 (90\%) mengalami penurunan jika dibandingkan kelompok P3 oleh karena akselerasi terhadap proses osifikasi telah terjadi. Hal ini seperti yang disebutkan Penn et al.(2012) bahwa ekspresi TGFß1 akan menurun saat memasuki fase remodelling.

\section{SIMPULAN DAN SARAN}

Ekspresi TGF $\beta 1$ meningkat setelah pemberian ekstrak gel Aloevera konsentrasi $45 \%, 60 \%, 90 \%$ pada soket alveolar pasca pencabutan gigi tikus wistar.

Diperlukan penelitian lebih lanjut terhadap peranan ekstrak gel Aloevera pada proses pasca pencabutan gigi dengan biomarker terhadap proses osifikasi.

\section{UCAPAN TERIMA KASIH}

1. Prof.Dr.Achmad Bashori,Drs.,MS.,Apt selaku guru besar departemen Farmakologi Fakultas Kedokteran Universitas Airlangga Surabaya dan sekaligus menjadi pembimbing 1. 
Jurnal Biosains Pascasarjana Vol. 20 (2018) pp

(C) (2018) Sekolah Pascasarjana Universitas Airlangga, Indonesia

2. Dr.Agung Krismariono,drg.,Sp.Perio(K) selaku pembimbing 2 .

3. Prof.Dr.,I Ketut Sudiana,Drs.,M.Si dan Dr.Sulistiawati,dr.,M.Kes selaku pengajar program magister Fakultas Kedokteran Universitas Airlangga Surabaya dan sekaligus menjadi konsultan dalam proses penelitian ini.

\section{Rujukan Jurnal}

1. Arijani E, Khoswanto C. The Use of 90\% Aloe vera Freeze Drying as The Modulator of Collagen Density On Extraction Socket of Incicivus Cavia cobaya.Dental Journal. 2008; 41(2): 74-6

2. Yuza F, Wahyudi A.I, Larnani S. 2014. Efek Pemberian Ekstrak Lidah Buaya (Aloe Barbadensis Miller) pada Soket Gigi terhadap Kepadatan Serabut Kolagen Pasca Ekstraksi Gigi Marmut (Cavia Porcellus). Maj Ked Gi. Desember 2014; 21(2): 127 - 135

\section{DAFTAR PUSTAKA}

Choi, B.W. Son, Y.S. Son, Y.I. Park, S.K.

Lee, M.H. Chung.2001. The woundhealing effect of a glycoprotein fraction isolated from aloe vera, $\mathrm{Br} . \mathrm{J}$. Dermatol. 145 (4).535-5545.

Jatnika, A. dan Saptoningsih. 2009. Meraup Laba dari Lidah Buaya. Jakarta: Agro Media Pustaka.Hal 1-26.
Jusuf AA.2009. Histoteknik Dasar. Bagan Histologi Fakultas Kedokteran Universitas Indonesia. [Tesis]. Jakarta, Universitas Indonesia.

Khoswanto.2016. Mekanisme Penyembuhan Luka Pencabutan Gigi Setelah Pemberian Ekstrak Etanol Daun Binahong (Andrera cordifolia (Ten) Steenis) Melalui Ekspresi HIF 1a, VEGF-A, dan BMP-2[Disertasi]. Surabaya : Fakultas Kedokteran Universitas Airlangga

M.D. Boudreau, F.a. a Beland, 2006.An evaluation of the biological and toxicological properties of Aloe barbadensis (miller), Aloe vera, J. Environ. Sci. Health. C. Environ. Carcinog. Ecotoxicol. Rev. 24 (1).103154.

Permatasari K; Andari W; Merina D.E.N. 2012. Efek Ekstra Ginseng Asia (Panax Ginseng) Pada Jumlah Sel Epitel Mukosa Soket Pasca Pencabutan Gigi Pada Rattus Norvegicus. Malang : Majalah FKUB

Poniatowski,L.A.,Wodjasiewicz,P.Gasik,Sz zukiewicz,D.2015. "Review Article: Transforming Growth Factor Beta Family:Insight Into The Role of Growth Factor in Regulation of Fracture Healing Biology and Potential Clinical Applications". Mediators of Inflamation. Penn,J.W,Grobbelaar,A.O.,Rolfe,K.J. 2012.

"Review Article:The Role of The 
Jurnal Biosains Pascasarjana Vol. 20 (2018) pp

(C) (2018) Sekolah Pascasarjana Universitas Airlangga, Indonesia

TGF $\beta$ Family in The Wound

Healing, Burns, and Scarring".

International Jornal of Burns and

Trauma.Vol 2/No 1

RISKESDAS. 2013. Laporan Hasil Riset

Kesehatan Dasar. Jakarta: Badan

Penelitian dan Pengembangan

Kesehatan. Kementerian Kesehatan RI

Sari PR.2018.Mekanisme Kerja Bone Graft dari

Kombinasi Cangkang Anadara granosa dan

Stichopus hermanni pada Penyembuhan

Tulang Alveolar Pasca Pencabutan Gigi

[Disertasi]. Surabaya: Fakultas Kedokteran

Universitas Airlangga

Sharma Priyanka, Amit C Kharkwal,

Harsha Kharkwal, M Z Abdin, Ajit Varm.

A Review on Pharmacological Properties of Aloe vera. Int. J. Pharm. Sci. Rev. Res., 29(2), November - December 2014; Article No. 07, Pages:

31-37

T. Reynolds and A. C. Dweck, "Aloe vera Leaf

Gel: A Review Update," Journal of Ethnopharmacology, Vol. 68, No. 1-3, 1999, pp. 3-37. http: //dx.doi.org/10. $\underline{1016 / \mathrm{S} 0378-8741(99) 00085-9}$

Wray, D. et al. 2003. Textbook of General and Oral Surgery. Churchill Livingstone, Toronto 